\title{
Climatic influence on demographic parameters of a tropical seabird varies with age and sex
}

\author{
Daniel Oro, ${ }^{1,3}$ Roxana Torres, ${ }^{2}$ Cristina Rodríguez, ${ }^{2}$ and Hugh Drummond ${ }^{2}$ \\ ${ }^{1}$ Population Ecology Group, Institut Mediterrani d'Estudis Avançats IMEDEA (CSIC-UIB), Miquel Marques 21, \\ 07190 Esporles, Mallorca, Spain \\ ${ }^{2}$ Instituto de Ecología, Universidad Nacional Autónoma de México, AP 70-275, 04510 D.F. Mexico
}

\begin{abstract}
In marine ecosystems climatic fluctuation and other physical variables greatly influence population dynamics, but differential effects of physical variables on the demographic parameters of the two sexes and different age classes are largely unexplored. We analyzed the effects of climate on the survival and recruitment of both sexes and several age classes of a long-lived tropical seabird, the Blue-footed Booby (Sula nebouxii), using longterm observations on marked individuals. Results demonstrated a complex interaction between yearly fluctuations in climate (both local and global indexes, during both winter and breeding season) and the sex and age of individuals. Youngest birds' survival and recruitment were commonly affected by local climate, whereas oldest birds' parameters tended to be constant and less influenced by environmental variables. These results confirm the theoretical prediction that sex- and age-related variation in life-history demographic traits is greater under poor environmental conditions, and they highlight the importance of including variability in fitness components in demographic and evolutionary models. Males and females showed similar variation in survival but different recruitment patterns, in relation to both age and the spatial scale of climatic influence (local or global). Results indicate different lifehistory tactics for each sex and different ages, with birds likely trying to maximize their fitness by responding to the environmental contingencies of each year.
\end{abstract}

Key words: Blue-footed Booby; capture-recapture modeling; climate; demography; life-history traits; population dynamic, seabird; Sula nebouxii.

\section{INTRODUCTION}

Climate notoriously correlates with oceanography, with large impacts on biological systems and their components (individuals, populations, communities, and ecosystems) (e.g., Root et al. 2003, Araújo and Rahbek 2006). Evidence of the influence of climate on population and community dynamics is abundant (Lima et al. 2001, Thomas et al. 2004); and crucial demographic parameters such as survival and fecundity have been shown to be affected by climatic forcing of bottomup trophic chains, from primary productivity to prey availability (Stenseth et al. 2002, Nevoux et al. 2008). This is especially true for marine systems, where oceanographic drivers may have direct and rapid effects on survival and fecundity (Stenseth et al. 2005, Harley et al. 2006). Seabirds are among the most studied models of the effects of oceanographic variability and climate on demographic parameters and population dynamics, and global oceanographic indexes (such as the North Atlantic Oscillation [NAO] and the Southern Oscillation Index [SOI], Durant et al. 2004) or local covariates (such as sea surface temperature [SST]) often explain temporal

Manuscript received 29 May 2009; revised 30 July 2009; accepted 5 August 2009. Corresponding Editor: J. P. Y. Arnould.

${ }^{3}$ E-mail: d.oro@uib.es variability in their survival (Jones et al. 2002, Sandvik et al. 2005, but see Tavecchia et al. 2007), recruitment (Votier et al. 2008), fecundity (Sydeman et al. 2001), breeding propensity (Jenouvrier et al. 2005, Lee et al. 2007), or population dynamics (Jenouvrier et al. 2003).

Much less is known about how climate differentially influences demographic parameters of the two sexes and different age classes (Coulson et al. 2001, Grosbois and Thompson 2005, Nevoux et al. 2007). Climatic conditions are likely to affect the availability of resources for foraging predators, and hence may influence decisions on how to optimally allocate energy at each age and by each sex. Effects of sex and, especially, age are strong in long-lived organisms (such as seabirds) because of their delayed maturity and high adult survival, and individuals become less vulnerable to climatic fluctuations as they acquire experience. Thus, in long-lived species differential influence of climate on age and sex classes can generate demographic heterogeneities with important consequences for population dynamics (Langvatn et al. 1996, Coulson et al. 2001, Jenouvrier et al. 2003). For example, differential effects of climate on survival or recruitment of the two sexes or different age classes may generate changes in operational sex ratio or competition among breeders, which in turn could affect population growth (e.g., Ezard et al. 2007, Becker et al. 2008). 
TABLE 1. Results of goodness-of-fit (GOF) tests of the general capture-recapture multistate (CMR) model.

\begin{tabular}{lrrrr}
\hline \hline Test component & \multicolumn{1}{c}{$\chi^{2}$} & $\mathrm{df}$ & $P$ & \multicolumn{1}{c}{$\hat{c}$} \\
\hline 3G SM & 296.590 & 61 & $<0.001$ & 4.86 \\
M ITEC & 246.490 & 27 & $<0.001$ & 9.13 \\
M LTEC & 82.943 & 34 & $<0.001$ & 2.44 \\
LRT (JMV vs. AS) & 1197.003 & 52 & $<0.001$ & 23.02 \\
Total & 1823.026 & 174 & $<0.001$ & 10.48
\end{tabular}

Note: Test components are as in Pradel et al. (2003); $\hat{c}$ is the inflation factor, i.e., $\chi^{2} / \mathrm{df}$.

We analyzed the impact of oceanographic (i.e., climatic) variability on survival and recruitment of the Blue-footed Booby Sula nebouxii, an apical predator in the tropical ocean. Importantly, the influence of environmental stochasticity was assessed using longitudinal records of several cohorts of marked individuals of both sexes, allowing analysis of effects of climate on different-aged individuals. Life-history theory states that individuals are constrained by limited energy that has to be allocated among components of their fitness (Stearns 1992). We expected the survival of immatures to be lower than that of adults, due to inexperience, poor foraging skills, and greater vulnerability to climatic variability (Jones et al. 2007, Votier et al. 2008). The curve of survival with age should follow a quadratic or logarithmic function, and age-related variation in survival should be greatest when environmental conditions are worst (Bunce et al. 2006, Oro et al. 2008). Female boobies are larger than males (see next section), and they show greater natal and breeding dispersal within the natal colony and provide more food to offspring (Osorio-Beristain and Drummond 1993, Guerra and Drummond 1995, Kim et al. 2007b). Greater body size could confer higher survival (e.g., Gaillard et al. 2000) unless associated with greater investment during breeding (Velando and Alonso-Alvarez 2003), and in a long-lived species, is expected to be associated with slightly later recruiting (Oro and Pradel 2000, Ludwigs and Becker 2005). Also, life-history theory predicts a trade-off between first breeding and future survival, with long-lived species deferring recruitment when environmental conditions are bad (Crespin et al. 2006). Hence, we expected that in poor climatic conditions, the curve of recruitment against age should be lower (with sexually mature individuals postponing recruitment) and differences between younger and older birds in recruitment should be greater (Bunce et al. 2006, Nevoux et al. 2007).

\section{Methods \\ Species and study site}

Blue-footed Boobies are socially monogamous (Osorio-Beristain and Drummond 1998), medium-sized sulids that breed colonially on islands in the tropical eastern Pacific Ocean. Both sexes plunge-dive for sardines and anchovies (Nelson 1978), foraging over a radius of up to 30 km (Anderson and Ricklefs 1987); females are larger and $32 \%$ heavier than males (1654 g vs. $1250 \mathrm{~g}$, respectively; Castillo and Chavez-Peón 1983). Exceptionally, these long-lived birds breed in the first year, but most recruit at two to six years of age (Drummond et al. 2003) and have broods of one to three chicks. Males and females spend similar time with clutch and brood and participate roughly equally in all aspects of parental care, except that females provide chicks with a greater mass of food (Guerra and Drummond 1995). Senescent decline in reproductive function begins at age 10 years (Velando et al. 2006b).

The study was conducted at Isla Isabel, Nayarit $\left(21^{\circ} 52^{\prime} \mathrm{N}, 105^{\circ} 54^{\prime} \mathrm{W}\right)$, off San Blas, Mexico. From 1988, fledglings were ringed annually in two fixed study areas in the colony and resighted as breeders during systematic monitoring of those areas during five months of every year between February and July through 2004. During these years, the colony held an average number of 971 breeding pairs. All birds with a clutch or brood were recorded, and identities were confirmed by up to three independent readings of each band during inspections of all nests every 3 or 6 days. Relative geographical isolation of the study colony, limited natal dispersal (median distance, males, $24.1 \mathrm{~m}$; females, 28.3 m; Osorio-Beristain and Drummond 1998), lifetime fidelity to the first breeding site (Kim et al. 2007a), and the rarity of resightings in other Mexican colonies (Castillo-Guerrero and Mellink 2007) suggested that permanent emigration from the study site was low, and that estimations of local demographic parameters probably suffer from little bias.

\section{Capture-recapture modeling}

We followed standard procedures for capture-recapture multistate modeling (CMR; Lebreton et al. 1992, Nichols and Kendall 1995), using M-SURGE software (Choquet et al. 2004). Three types of parameters were involved: survival probabilities $(S)$, transition probabilities between states (from nonbreeder " $n$ " to breeder " $b$," i.e., recruitment, noted by $\psi^{n b}$ ), and resighting probabilities $(p)$. Birds were sexed when they recruited, and individuals that never recruited could not be sexed. To overcome this limitation, we considered three states: state 1 is a nonbreeder, states 2 and 3 are breeding male and breeding female, respectively. Transitions between state 1 and both states 2 and 3 correspond to recruitment probabilities for males and females, respectively. Consequently, we set at 0 the recapture probability of state 1 (since only breeders were resighted), the transition between states 2 and 3 (i.e., change of sex), and the transitions from states 2 and 3 to state 1 (birds were only resighted as breeders). The modeling was carried out in three consecutive steps: first, the search of an umbrella model to start with. A consensual model was then built to avoid overparameterized models with large number of parameters due to the interaction of all factors considered. Finally, we tested the influence of oceanographic variables separately for each demograph- 
ic parameter (survival and recruitment), each sex, and each age class contained in the consensual model to end up with a selected model.

We first tested the goodness of fit (GOF) of a general multistate model, the Arnason-Schwarz model, consisting of two basic components: (1) test $3 \mathrm{G}$, which tests the dependence on the previous capture history for individuals released at same time; and (2) testM, which tests the dependence on current capture (Pradel et al. 2003). The GOF test was carried out using the U-CARE program (Choquet et al. 2003), skipping the subcomponents WBWA and TEST3.SR to account for the agedependence structure. The fit of these more general models was poor (see inflation factor, $\hat{c}$, in Table 1), likely due to an age structure in survival, transition, and recapture probabilities; but it was not possible to test the fit of a model with a full interaction of time and age, all parameters being different. An alternative was to run a separate GOF test for each cohort and sum all the tests, but breeding failure or very low breeding success in some years prevented this. To overcome this problem, we ran several GOF tests modifying the original capturerecapture histories for each age structure: For instance, for age 2, we removed observations before age 2, deleting the previous observations at 1 year of age (e.g., the CMR histories 10222020 and 13330333 were transformed in the histories 00222020 and 00330333 , respectively, while the history 00000100 was deleted from the analysis). We expected a progressive reduction in the inflation factor $\hat{c}$ (i.e., an improvement in the fit) together with an increase in age in the modified capturerecapture histories, due to greatly reduced potential effects (transients, trap dependence) of age on survival, and on transition and recapture probabilities. An acceptable $\hat{c}$ value of 1.86 was achieved with a structure of seven age classes (birds between 7 years and 16 years old were pooled; see Fig. 1), and this $\hat{c}$ value was applied to all models, starting with the more general model $\left[S_{7 a^{*} t^{*} s}, \psi_{7 a^{*} t^{*} s}^{n b}, p_{7 a^{*} t^{*} s}\right]$. In those models, the factors considered were age (seven values), time (16 values for the years 1989-2004), and sex (two values), denoted by $a, t$, and $s$, respectively. Interactions between terms were denoted in models by an asterisk (*), additive effects by a plus sign $(+)$, and no time variation by a multiplier dot $(\cdot)$. The next step was to find a consensual model (Tavecchia et al. 2005), i.e., a more parsimonious model than the more general model, with its high number of potential combinations of factors (time, age, and sex) for each of the parameters (survival, transition, and recapture). The consensual model was selected for each parameter by progressively eliminating effects while keeping the structure of the other parameters as general as possible. Consensual models were the umbrella models used to test for influence of climatic variables.

Selection of the best model followed standard procedures by looking for parsimony between the number of parameters and the deviance of the model, using a second-order Akaike's Information Criterion

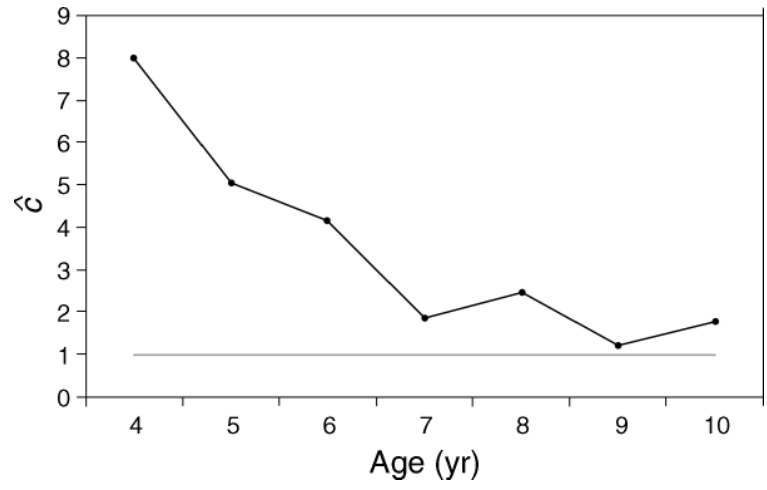

FIG. 1. Inflation factor values $(\hat{c})$ calculated for each goodness-of-fit (GOF) test run for each set of age-modified capture-recapture histories (see Methods) for Blue-footed Boobies (Sula nebouxii). Only tests run for ages 4-10 years are shown. The gray line of best fit (i.e., no overdispersion, $\hat{c} \approx$ 1 ) is also shown for reference. Although a structure with nine age classes was closest to 1 , we considered that seven age classes were sufficient to account for most overdispersion, and we applied a $\hat{c}$ value of 1.86 to all our models.

$\left(\right.$ QAIC $_{c}$; see Lebreton et al. 1992, Burnham and Anderson 2002). Models that did not differ in more than four values of $\mathrm{AIC}_{\mathrm{c}}\left(\Delta \mathrm{AIC}_{\mathrm{c}}\right)$ were considered statistically equivalent.

\section{Testing the influence of time and climatic covariates on age-related demographic parameters}

We tested the importance of climatic covariates (relative to time) as potential influences on survival and recruitment. We used two covariates that differ in their spatial scale: sea surface temperature $55 \mathrm{~km}$ southeast of the booby colony (SST; obtained from Columbia University database, available online), ${ }^{4}$ which was based on the foraging range of the study species (Anderson and Ricklefs 1987). The second covariate was the Southern Oscillation Index (SOI; Australian Bureau of Meteorology, available online), ${ }^{5}$ expressing El Niño/ La Niña oscillations in terms of variation in sea-level air pressure across the tropical Pacific region. We selected values for two clearly differentiated periods: the breeding season (January through July, denoted by $\mathrm{SSTb}$ and SOIb for local and general oceanographic conditions, respectively), and the wintering season, during which birds mostly stay around the colony (October through December, noted by SSTw and SOIw). In the breeding season, birds incur high energetic costs of territory establishment and defense, pairing, egg formation, incubation, and brood care, with potential consequences for current recruitment and future survival. Oceanographic conditions could also be critical during wintering, when delayed costs of reproduction are expressed and fledglings and yearlings face the challenges of independence (see next paragraph). We

\footnotetext{
${ }^{4}\langle$ http://ldeo.columbia.edu $\rangle$

5 http://www.bom.gov.au/climate/current/soihtm1.shtml $\rangle$
} 
TABLE 2. Spearman rank correlations between the oceanographic variables sea surface temperature (SST) and Southern Oscillation Index (SOI) used in the analysis of survival and recruitment in Blue-footed Boobies (Sula nebouxii) at Isla Isabel, Mexico, in the breeding and wintering seasons during 1988-2004.

\begin{tabular}{|c|c|c|c|c|c|c|c|c|c|}
\hline \multirow[b]{2}{*}{ Variable } & \multicolumn{3}{|c|}{ SST wintering } & \multicolumn{3}{|c|}{ SOI breeding } & \multicolumn{3}{|c|}{ SOI wintering } \\
\hline & $\rho$ & $P$ & $N$ & $\rho$ & $P$ & $N$ & $\rho$ & $P$ & $N$ \\
\hline SST breeding & 0.606 & 0.008 & 17 & -0.809 & 0.001 & 16 & -0.267 & 0.284 & 17 \\
\hline SST wintering & & & & -0.370 & 0.144 & 16 & -0.556 & 0.017 & 17 \\
\hline SOI breeding & & & & & & & 0.27 & 0.918 & 16 \\
\hline
\end{tabular}

Note: All tests were two-tailed, and statistically significant correlations $(P<0.05)$ are shown in boldface; $\rho$ coefficient was the Spearman Rank correlation value; $N$ was the sample size.

analyzed correlations among climatic covariates to test for potential, noisy colinearity (Grosbois et al. 2008); we did not perform a PCA analysis to reduce the number of covariates (e.g., Veran et al. 2007) because we only dealt with four variables. Although local and general indexes (SST and SOI) were in general correlated during both the breeding season and the wintering season (Table 2), in exceptional years, SST values were independent of SOI oscillations. Furthermore, while SST values in the breeding season and the following wintering season were correlated, this was not the case for SOI values (Table 2).

We tested the influence of each climatic variable on each age class, starting with the consensual model. We compared all possible models with a climatic factor with the corresponding model for each age class varying with time using $\Delta \mathrm{AIC}_{\mathrm{c}}$ values. For each age class, the covariates that better replaced time (from models with $\left.\Delta \mathrm{AIC}_{\mathrm{c}}<4\right)$ were retained and used in final models that included all retained climatic variables together. The proportion of variance explained by each selected covariate was calculated except when the model with constant value of the age class was better than the timedependent value of such age class (see Results). To calculate the impact of a covariate $X$ on the age-related parameter $\varpi$, we performed an analysis of deviance test with a Fisher-Snedecor distribution (ANODEV) by comparing the amount of deviance between the model

TABLE 3. Building a consensual model (see Methods) by modeling survival $(S)$, recruitment $(\psi)$, and resighting $(p)$ probabilities in the Blue-footed Booby on Isla Isabel, starting from the umbrella model $\left[S_{7 a^{*} t_{s}}^{n}, \psi_{7 a^{*} t^{*} s}^{n b}, p_{7 a^{*} t_{*}^{*}}^{n}\right]$.

\begin{tabular}{|c|c|c|c|c|c|}
\hline Model & $\mathrm{np}$ & Dev & $\mathrm{QAIC}_{\mathrm{c}}$ & $\Delta_{i}$ & $w_{i}$ \\
\hline Umbrella model $S_{7 a^{*} t^{*} \mathrm{~s}}^{n}, \psi_{7 a^{*} *^{*} \mathrm{~s}}^{n b}, p_{7 a^{*} t^{*} \mathrm{~s}}^{n}$ & 327 & 26678.838 & 14997.4613 & & \\
\hline \multicolumn{6}{|l|}{ Survival } \\
\hline$S_{7 a^{*} s}$ & 259 & 26833.711 & 14944.726 & -52.735 & 0.001 \\
\hline$S_{7 a^{*} t}$ & 293 & 26725.121 & 14954.344 & -43.117 & 0.000 \\
\hline$S_{7 a}$ & 254 & 26915.382 & 14978.636 & -18.826 & 0.000 \\
\hline$S_{7 a+t^{*} s}$ & 281 & 26731.551 & 14933.801 & -63.660 & 0.168 \\
\hline$S_{7 a+t}$ & 265 & 26785.132 & 14930.608 & -66.853 & 0.829 \\
\hline$S_{7 a+s}$ & 255 & 26844.298 & 14942.418 & -55.043 & 0.002 \\
\hline \multicolumn{6}{|l|}{ Recruitment } \\
\hline$\psi_{7 a^{*} s}$ & 302 & 26737.217 & 14978.848 & -18.614 & 0.031 \\
\hline$\psi_{7 a^{*} t}$ & 305 & 26734.636 & 14983.460 & -14.001 & 0.003 \\
\hline$\psi_{7 a}$ & 249 & 27089.013 & 15061.985 & 64.524 & 0.000 \\
\hline$\psi_{7 a+t^{*} s}$ & 312 & 26704.615 & 14972.073 & -25.389 & 0.930 \\
\hline$\psi_{7 a+t}$ & 299 & 26746.010 & 14977.576 & -19.886 & 0.059 \\
\hline$\psi_{7 a+s}$ & 297 & 26760.944 & 14981.604 & -15.857 & 0.008 \\
\hline \multicolumn{6}{|l|}{ Resighting } \\
\hline$p_{7 a^{*} s}$ & 259 & 28165.348 & 15660.660 & 663.200 & 0.000 \\
\hline$p_{7 a^{*} t}$ & 293 & 26876.749 & 15035.865 & 38.404 & 1.000 \\
\hline$p_{7 a}$ & 254 & 28574.126 & 15870.433 & 872.97 & 0.000 \\
\hline$p_{7 a+t^{*} s}$ & 279 & 27594.670 & 15393.844 & 396.38 & 0.000 \\
\hline$p_{7 a+t}$ & 265 & 27260.372 & 15186.114 & 188.65 & 0.000 \\
\hline$p_{7 a+s}$ & 255 & 27926.367 & 15524.176 & 526.71 & 0.000 \\
\hline Consensual model $S_{7 a+t}^{n}, \psi_{7 a+t^{*} \mathrm{~s}}^{n b}, p_{7 a^{*} *_{\mathrm{*}} \mathrm{s}}^{n}$ & 210 & 26897.652 & 14881.103 & -116.36 & \\
\hline
\end{tabular}

Notes: For each parameter, the selected model is in boldface, except for resighting probabilities, for which the umbrella model was not improved. Abbreviations are: np, number of estimable parameters; Dev, relative deviance of each model; $\mathrm{QAIC}_{\mathrm{c}}$, Akaike Information Criterion corrected for $\hat{c} ; \Delta_{i}, \mathrm{QAIC}_{\mathrm{c}}$ difference between current model and umbrella model; and $w_{i}$, current model weight for each group of models for survival, recruitment, and resighting parameters. In the models, abbreviations are: $n$, nonbreeders; $b$, breeders; $a$, age; $t$, time; and $s$, sex. The age class $7 \mathrm{a}$ represents a grouping of birds $7-16$ years old. 
TABLE 4. Modeling the influence of climate covariates on survival $(S)$ and recruitment $(\psi)$ probabilities of each age class of the Blue-footed Booby on Isla Isabel during 1988-2004.

\begin{tabular}{|c|c|c|c|c|c|c|c|c|c|c|}
\hline \multirow{2}{*}{$\begin{array}{l}\text { Demographic } \\
\text { parameter }\end{array}$} & \multirow{2}{*}{$\begin{array}{c}\text { Age } \\
\text { class (yr) }\end{array}$} & \multirow[b]{2}{*}{ Dev } & \multirow[b]{2}{*}{$\mathrm{np}$} & \multirow[b]{2}{*}{$\mathrm{QAIC}_{\mathrm{c}}$} & \multicolumn{4}{|c|}{ Climate covariates, $\Delta \mathrm{AIC}_{\mathrm{c}}$} & \multirow[b]{2}{*}{ Constant } & \multirow[b]{2}{*}{$r^{2}$} \\
\hline & & & & & $\mathrm{SOIb}$ & SOIw & $\mathrm{SSTb}$ & SSTw & & \\
\hline Survival & $\begin{array}{r}1 \\
2 \\
3 \\
4 \\
5 \\
6 \\
>6\end{array}$ & $\begin{array}{l}26825.71 \\
26815.66 \\
26813.43 \\
26780.01 \\
26864.03 \\
26917.85 \\
26887.72\end{array}$ & $\begin{array}{l}220 \\
219 \\
220 \\
221 \\
222 \\
221 \\
221\end{array}$ & $\begin{array}{l}14864.42 \\
14855.02 \\
14855.82 \\
14882.90 \\
14886.24 \\
14914.00 \\
14897.80\end{array}$ & $\begin{array}{r}12.0 \\
53.7 \\
12.6 \\
-16.8 \\
23.3 \\
-16.6 \\
-5.3\end{array}$ & $\begin{array}{r}4.7 \\
22.5 \\
-6.3 \\
-16.8 \\
-2.1 \\
3.0 \\
1.1\end{array}$ & $\begin{array}{r}17.9 \\
18.6 \\
31.8 \\
-8.6 \\
29.6 \\
-2.6 \\
-0.7\end{array}$ & $\begin{array}{r}-2.0 \\
-7.3 \\
-9.9 \\
-25.3 \\
-14.6 \\
-29.0 \\
-20.4\end{array}$ & $\begin{array}{r}18.7 \\
48.3 \\
25.0 \\
-4.1 \\
22.4 \\
-\mathbf{2 7 . 0} \\
-\mathbf{2 3 . 0}\end{array}$ & $\begin{array}{l}0.813 \\
0.673 \\
0.570 \\
0.516 \\
0.757\end{array}$ \\
\hline Recruitment, males & $\begin{array}{r}1 \\
2 \\
3 \\
4 \\
5 \\
6 \\
>6\end{array}$ & $\begin{array}{l}26877.63 \\
26897.81 \\
27022.00 \\
26864.49 \\
26874.94 \\
26917.20 \\
26891.30\end{array}$ & $\begin{array}{l}217 \\
219 \\
212 \\
220 \\
220 \\
221 \\
222\end{array}$ & $\begin{array}{l}14884.34 \\
14899.19 \\
14951.96 \\
14883.28 \\
14888.89 \\
14913.61 \\
14901.69\end{array}$ & $\begin{array}{r}-3.6 \\
-15.6 \\
-67.5 \\
14.0 \\
54.5 \\
36.4 \\
-15.7\end{array}$ & $\begin{array}{r}3.4 \\
-13.5 \\
-68.8 \\
13.6 \\
43.0 \\
98.0 \\
-21.3\end{array}$ & $\begin{array}{r}-3.7 \\
1.2 \\
-51.2 \\
88.3 \\
54.7 \\
8.9 \\
-\mathbf{2 6 . 5}\end{array}$ & $\begin{array}{r}-9.1 \\
-10.1 \\
-74.6 \\
69.9 \\
51.1 \\
18.3 \\
-20.0\end{array}$ & $\begin{array}{r}-4.6 \\
-27.0 \\
-78.9 \\
-4.3 \\
-3.9 \\
-29.3 \\
-2.9\end{array}$ & 0.243 \\
\hline Recruitment, females & $\begin{array}{r}1 \\
2 \\
3 \\
4 \\
5 \\
6 \\
>6\end{array}$ & $\begin{array}{l}26883.19 \\
27007.26 \\
27022.00 \\
26867.87 \\
26858.37 \\
26885.64 \\
26889.81\end{array}$ & $\begin{array}{l}219 \\
220 \\
212 \\
219 \\
219 \\
220 \\
219\end{array}$ & $\begin{array}{l}14891.33 \\
14960.03 \\
14951.96 \\
14883.09 \\
14877.98 \\
14894.64 \\
14894.89\end{array}$ & $\begin{array}{r}13.2 \\
-91.2 \\
-\mathbf{6 6 . 0} \\
-\mathbf{1 0 . 4} \\
-\mathbf{2 . 3} \\
-\mathbf{1 5 . 3} \\
-\mathbf{1 0 . 8}\end{array}$ & $\begin{array}{r}4.3 \\
-58.7 \\
-57.2 \\
16.3 \\
15.9 \\
-10.5 \\
-8.5\end{array}$ & $\begin{array}{r}17.1 \\
-70.1 \\
-57.7 \\
21.1 \\
10.9 \\
0.1 \\
2.4\end{array}$ & $\begin{array}{r}2.9 \\
-82.6 \\
-\mathbf{6 4 . 6} \\
0.7 \\
6.9 \\
-10.5 \\
-7.5\end{array}$ & $\begin{array}{r}-\mathbf{1 8 . 2} \\
-78.0 \\
-59.5 \\
3.7 \\
18.0 \\
3.8 \\
-\mathbf{1 3 . 2}\end{array}$ & $\begin{array}{l}0.543 \\
0.593 \\
0.472 \\
0.367 \\
0.608\end{array}$ \\
\hline
\end{tabular}

Notes: Since we started from the consensual model ([ $\left.S_{7 a+t}^{n}, \psi_{7 a+t^{*} s}^{n b}, p_{7 a^{*} *^{*} s}^{n}\right]$; see Table 3 for abbreviations), we modeled covariates (in the place of time) in survival and recruitment. Numbers below climate covariates show the $\Delta \mathrm{AIC}_{\mathrm{c}}$ of the current model for each covariate with the corresponding model for each age class. The covariates that better replaced time for each age class and parameter are shown in boldface (considering equivalent models those with $\Delta \mathrm{AIC}_{\mathrm{c}}<4$ ); $r^{2}$ refers to the proportion of variance explained by the covariate (ANODEV; see Methods), except for age classes in which the constant model showed the lowest absolute $\Delta \mathrm{AIC}_{\mathrm{c}}$ with respect to the time-varying model. SST is sea surface temperature, and SOI is Southern Oscillation Index; b is breeding season, and $\mathrm{w}$ is winter.

assuming full time dependence, the model including the covariate $X$, and the one assuming no time variation (noted by $\cdot$ ) through the ratio [deviance $\varpi(\cdot)$ - deviance $\varpi(X)] /[$ deviance $\varpi(\cdot) /$ deviance $\varpi(t)]$.

\section{RESULTS}

We built the capture-recapture histories of 6243 individuals for the period from 1988 to 2004, of which $37 \%$ recruited (were resighted at least once as a breeder), including males and females in nearly equal proportions (51\% and $49 \%$, respectively).

\section{Consensual model}

The search for a consensual model revealed an additive effect of time for survival (a potential effect of sex was also present, but not considered in view of its model weight) and an additive effect of time and sex (in interaction) on age for recruitment, while none of the different combinations of factors used to model recapture probability improved the umbrella model (Table 3). The ranking of models and the $\triangle \mathrm{QAIC}$ values were very similar when optimal, rather than full, parameterization of the other two parameters was used (results not shown). Thus, the consensual model $\left[S_{7 a+t}^{n}\right.$, $\left.\psi_{7 a+t^{*} s}^{n b}, p_{7 a^{*} t^{*} s}^{n}\right]$ was provisionally taken as the best model for testing the effects of climatic covariates on survival (equally for the two sexes) and recruitment (differently for each sex).

\section{Influence of climate on age classes}

The influence of climatic variables on survival and recruitment varied with age, and was strongest in the youngest or oldest classes depending on the parameter and the sex (Table 4): for instance, winter climate at local scale (i.e., SSTw) influenced survival of all age classes except the oldest ones ( $>5$ years old), for which a constant model was supported, as well as a model with any covariate. ANODEV analyses showed that covariates explained high percentages of the difference in deviance between time-varying models (i.e., including climate covariates) and constant models (not shown), especially for youngest birds (Table 4).

The probability of male recruitment of the youngest and oldest age classes was more influenced by climate than that of 2-, 3-, 4-, and 5-year-old birds. For instance, warm local water (SST) depressed recruitment of males of all age classes, and this effect was especially strong for youngest birds facing warm water in the previous winter and oldest birds facing warm water during breeding (Table 4, Fig. 2A).

On the basis of these associations, we tested the fit of more ad hoc models of climatic influences on the survival and recruitment of particular age classes. We also tested for potential linear or quadratic influence of climatic covariates on each age class (noted by $A$ and $A^{2}$ respectively; see models 3 to 6 in Table 5). None of these models improved the consensual model, but the best 

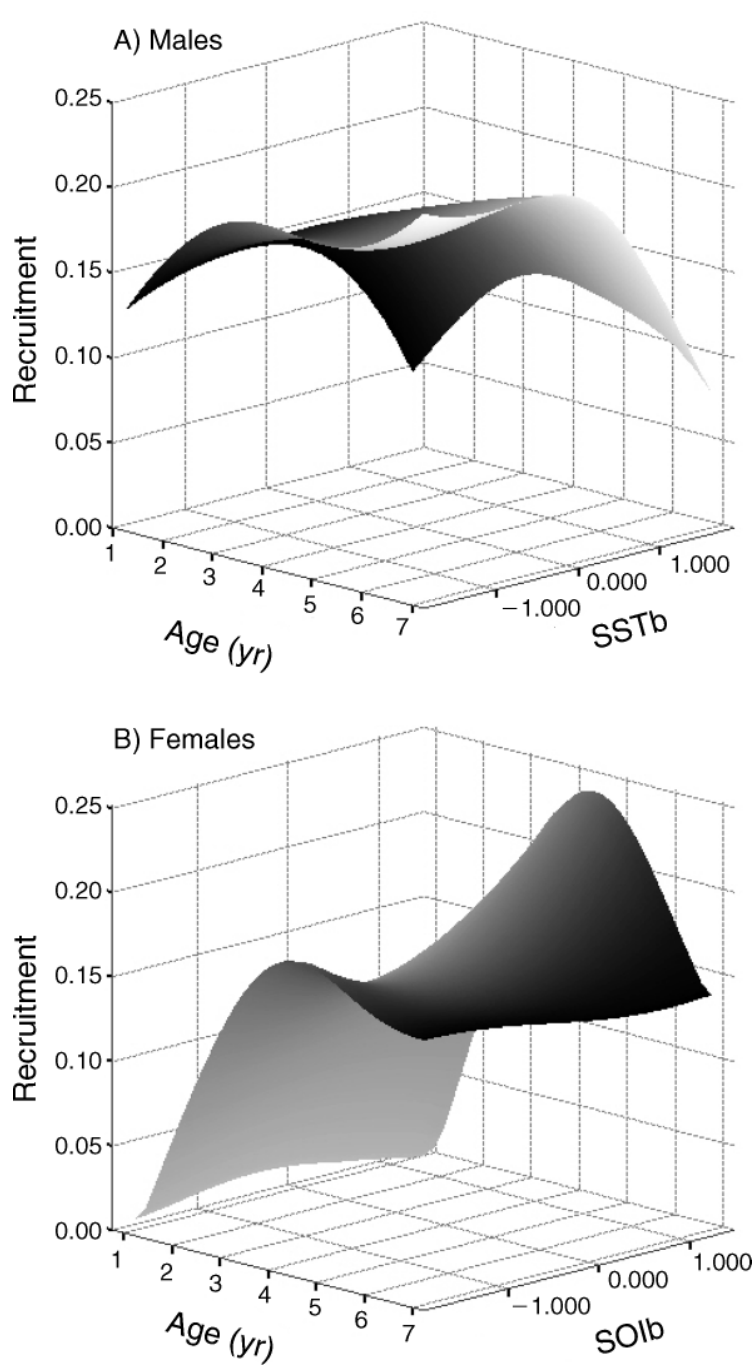

FIG. 2. Probability of recruitment of Blue-footed Boobies at Isla Isabel, Mexico, depending on sex, age, and climatic conditions (standardized indexes). A smoothing regression surface using a lowess method by iteration of weighted least squares on such estimates (Simonoff 1996) was drawn for interpretation. Birds 7-16 years old were grouped in a single age class. Estimates were obtained from model $\left[S_{15 a+t>5 a}\right.$. $\left.\psi_{1 a^{*} t, 2 \_6 a, a 7^{*} t}^{n b m}, \quad \psi_{1 a \cdot, 2 \_6 a+t, a 7 .}^{n b f}, p_{7 a^{*} t^{*} s}\right]$ for (A) males and (B) females. For each sex, we show the more influential climatic index: sea surface temperature during breeding season (SSTb) vs. Southern Oscillation Index (SOIb; see also Tables 2 and 4 and Results). (See also Capture-recapture modeling for clarification of abbreviations.)

model (model 2; Table 5) explained $44 \%$ of the variance of the corresponding time-varying model $\left[S_{1 \_5 a+t,>5 a}\right.$, $\left.\psi_{1 a^{*} t, 2 \_6 a \cdot a 7^{*} t}^{n b m}, \psi_{1 a \cdot, 2 \_6 a+t, a 7 \cdot,}^{n b f} p_{7 a^{*} t^{*} s}\right]$, which was taken as the reference model to show estimates of demographic parameters. Paradoxically, the lack of improvement was probably the result of having robust estimates (i.e., with low confidence intervals and narrow ranges) of survival and recruitment due to high resighting rates, especially after birds reached three years of age (Fig. 3); when this occurs, it is difficult to improve the time-dependent model by substituting a climatic covariable in place of time (R. Pradel, personal communication).

\section{Climate and age effects on survival}

Annual survival of Blue-footed Boobies did not differ between the sexes (see the consensual model). Warm winter water depressed survival of both sexes much more in the first few years of life than at older ages (Fig. 4 ). When the water was warm, survival rate increased sharply with age, with birds older than six years showing a mean value of $0.850(\mathrm{SE}=0.017)$, and youngest birds showing values as low as $0.535(\mathrm{SE}=0.254)$. When the water was cool, survival rates of all age classes improved, modestly in birds older than six years, to $0.891(\mathrm{SE}=0.017)$ and substantially in the youngest birds, to $0.755(\mathrm{SE}=0.186)($ Fig. 4$)$.

\section{Climatic, age, and sex effects on recruitment}

Probability of recruitment varied with age and climate, but differently in the two sexes (Table 4, Fig. 2). Intermediate-aged males were little affected by climate, but old males were most likely to recruit when the local water was cool in the breeding season (Fig. $2 \mathrm{~A}$ ), and young males recruited only when the local water was cool in the previous winter (see also Table 4). Intermediate-aged females had the highest probability of recruiting and were more likely to recruit when the SOI index was high during the breeding season (see also Fig. 2B). Young females were considerably less likely to recruit than old females, and neither young nor old females were affected by climate (Table 4 ).

\section{DisCusSION}

Demographic parameters of the Blue-footed Booby are more strongly associated with local climatic conditions than with global environmental conditions. This result reflects the weak colinearity between indexes at different spatial scales: extreme El Niño events across the Pacific Ocean did not reliably predict extremely warm waters around the study site. Global climatic indexes may be strongly related to demographic parameters of species that forage far from the colony or migrate over great distances during the nonbreeding season, such as guillemots, shearwaters, albatrosses, and migratory passerines (Sillett et al. 2000, Nevoux et al. 2007, Votier et al. 2008); whereas local climate may be more related to the demography of species that forage and disperse locally, such as shags, gulls, and boobies (Frederiksen et al. 2004, Velarde et al. 2004).

Analysis of demographic parameters in structured populations (with sex- and age-specific partitioning of energy investment) potentially provides the best insight into how climate shapes complex population dynamics (Coulson et al. 2001). The high annual survival of boobies and early recruitment of some individuals provided a rare opportunity to estimate how age and sex affect the impact of climate on two important demographic parameters (Thompson and Grosbois 
TABLE 5. Modeling the effects of climatic covariates on survival and recruitment of Blue-footed Boobies at Isla Isabel altogether on each age class following results from Table 4 and compared with the consensual model $\left[S_{7 a+t}^{n}, \psi_{7 a+t^{*} s}^{n b}, p_{7 a^{*} t^{*}}^{n}\right]$.

\begin{tabular}{|c|c|c|c|c|c|c|c|c|}
\hline Model & Survival & Recruitment males & Recruitment females & $\mathrm{np}$ & Dev & $\mathrm{QAIC}_{\mathrm{c}}$ & $\Delta i$ & $r^{2}$ \\
\hline $\begin{array}{l}\text { Consensual model: } \\
S_{7 a+t}^{n}, \psi_{7 a+t^{*} \mathrm{~s}}^{n b}, p_{7 a^{*} *^{*} \mathrm{~s}}^{n}\end{array}$ & & & & 210 & 26897.6517 & 14881.103 & & \\
\hline 1 & $1 \_5_{\mathrm{SSTw}}, 6 \cdot, \geq 7$. & $1_{\mathrm{SSTw}}, 2 \_6 \cdot, \geq 7_{\mathrm{SSTb}}$ & $1 \cdot, 2 \_6_{\text {SOIb }}, \geq 7$. & 185 & 27095.469 & 14935.456 & 54.35 & 0.288 \\
\hline 2 & $1 \_5_{\text {SSTw }},>5$. & $1_{\text {SSTw }}, 2_{-} 6, \geq 7_{\text {SSTb }}$ & $1,2 \_6_{\text {SOIb }}, \geq 7$. & 184 & 27002.745 & 14904.487 & 23.38 & 0.442 \\
\hline 3 & $1 \_5 \mathrm{~A}_{\mathrm{SSTw}}^{2},>5$. & $1_{\mathrm{SSTw}}, 2 \_6 \cdot, 7_{\mathrm{SSTb}}$ & $1,2{ }_{-} 6_{\text {sOIb }}, \geq 7$. & 176 & 27131.405 & 14938.777 & 57.67 & 0.158 \\
\hline 4 & $1 \_5 \mathrm{~A}_{\mathrm{SSTw}},>5$. & $1_{\mathrm{SSTw}}, 2 \_6 \cdot, \geq 7_{\mathrm{SSTb}}$ & $1 \cdot, 2 \_6_{\text {SOIb }}, \geq 7$ & 175 & 27222.048 & 14987.510 & 106.41 & 0.080 \\
\hline 5 & $1 \_5 \mathrm{~A}_{\text {SSTw }}^{2},>5$. & $1_{\mathrm{SSTw}}, 2 \_6 \cdot, \geq 7_{\mathrm{SSTb}}$ & $1 \cdot, 2 \_6 \mathrm{~A}_{2}^{2} \mathrm{SOIb}, \geq 7$. & 174 & 27302.888 & 15056.113 & 175.01 & 0.001 \\
\hline 6 & $1 \_5_{\mathrm{SSTw}},>5$. & $1_{\mathrm{SSTw}}, 2 \_6 \cdot, \geq 7_{\mathrm{SSTb}}$ & $1 \cdot, 2 \_6 \mathrm{~A}_{\text {sOIb }}^{2}, \geq 7$. & 177 & 27140.242 & 14945.528 & 64.42 & 0.102 \\
\hline
\end{tabular}

Notes: An interaction of any factor with a range of age classes is shown by “_"; for instance, 1_5 means an age class grouping birds from 1 to 5 years old. When a trend in age (linear or quadratic) was used instead, this is shown by $\mathrm{A}$ and $\mathrm{A}^{2}$, respectively. In all models, resighting probability was kept as the consensual model, i.e., depending on the interaction of age, time, and sex. The best model is shown in boldface (model 2); none of these climatic models improved the consensual model (see Methods and Table 3), even though some of them explained a relatively high percentage of the variance (see Results). SST is sea surface temperature, and SOI is Southern Oscillation Index; b is breeding season, and w is winter.

2002). The effect of climate on survival varies strongly with age, and the effect of climate on recruitment depends on both age and sex, and sexual and age class differences are exacerbated by harsher climate (see also Nevoux et al. 2007).

\section{Climate and age effects on survival}

Survival of both sexes depended heavily on winter climate: The coolest winter waters were associated with roughly $90 \%$ survival in all age classes except the
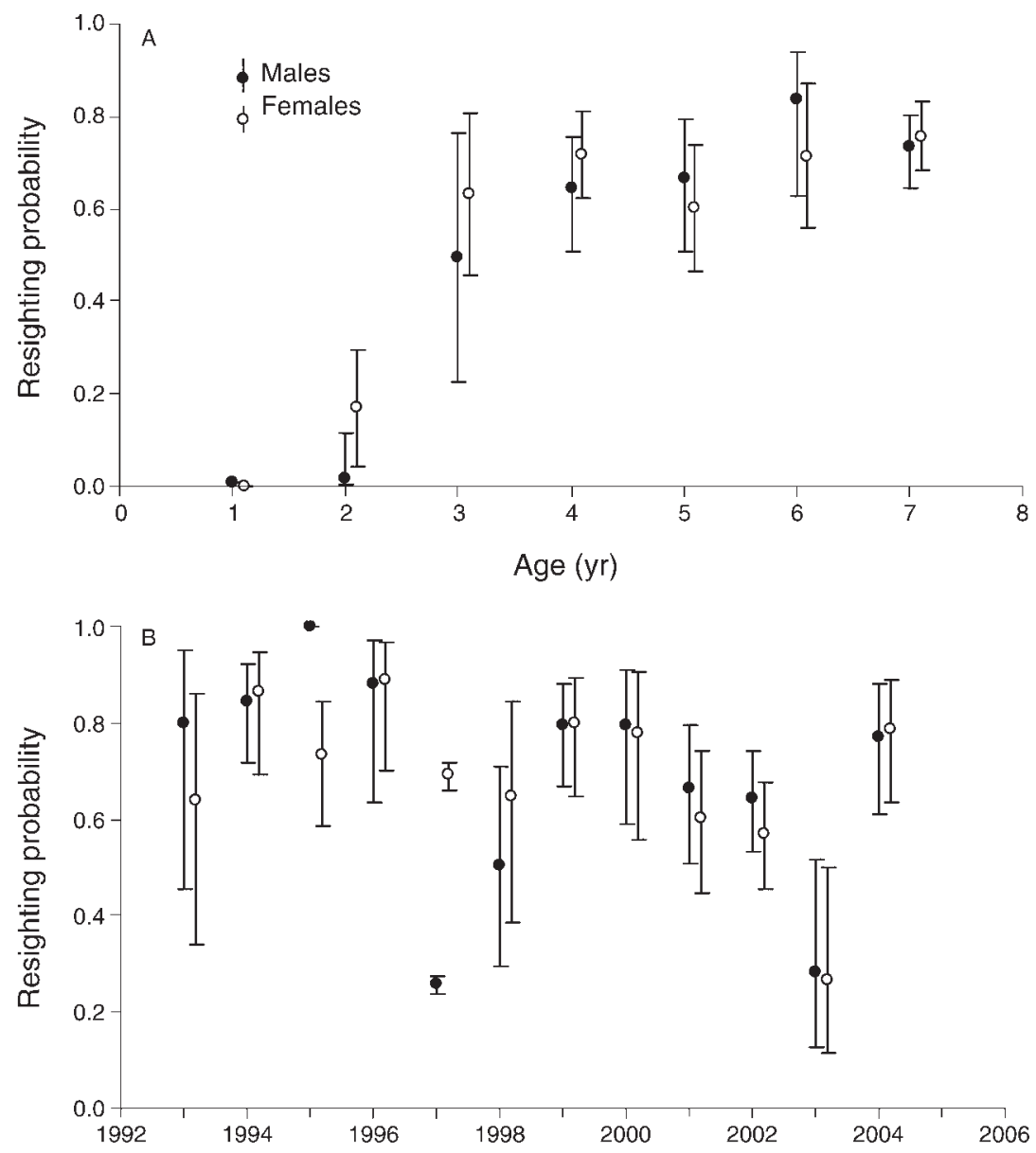

FIG. 3. Estimates of resighting probabilities (with 95\% confidence intervals) of Blue-footed Boobies at Isla Isabel during 1988 2004. (A) Variation with age in males (solid circles) and females (open circles), taking 2001 as an example. (B) Variation with time in males and females, taking five-year-old birds as an example. No difference between the sexes was found. 


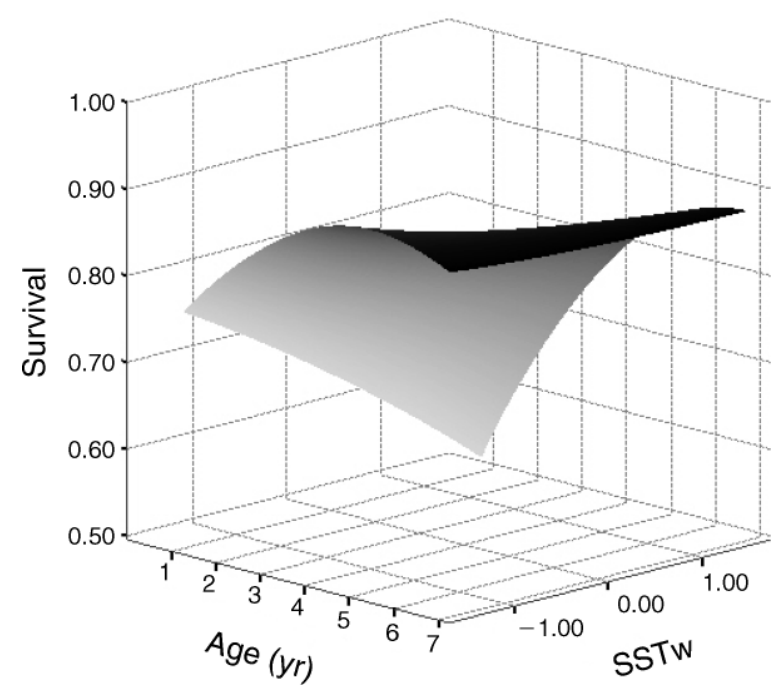

FIG. 4. Variation in survival with age and climatic index (standardized sea surface temperature during the winter; SSTw) of male and female Blue-footed Boobies at Isla Isabel, during 1988-2004. Values were estimated from model $\left[S_{1 \_5 a+t,>5 a}^{r}\right.$, $\psi_{1 a^{*} t, 2 \_6 a, a 7^{*} t}^{n b m}, \psi_{1 a \cdot, 2 \_6 a+t, a 7 \cdot,}^{n b f} p_{7 a^{*} t_{*} *_{s}}^{r}$, and a smoothing regression surface using a lowess method by iteration of weighted least squares on such estimates was drawn for interpretation. Note that survival of the oldest age classes (7-16 yr) was largely independent of variation in SSTw (and Southern Oscillation Index, SOI; see Table 4).

youngest birds (one year old), and the warmest winter waters depressed survival, slightly in the case of the oldest birds (7-16 years old) and severely in the case of the youngest birds. Young individuals of long-lived species generally show relatively poor survival (Jones et al. 2007), and young marine birds tend to forage inefficiently. Young boobies may suffer relatively high mortality because inexperience probably makes them inefficient foragers and plunge-divers, and also because younger age classes include relatively higher proportions of poor quality individuals (Nevoux et al. 2007, Sanz et al. 2008). Young boobies also showed relatively high variance in annual survival, possibly implying a special vulnerability of inexperienced birds to environmental stochasticity and a high heterogeneity in individual quality, later reduced by selection pressures (Sanz et al. 2008). Climate is an important selective force for young boobies and cohorts that experience cold years early in the life should be better represented in the population than others.

\section{Climatic, age, and sex effects on recruitment}

Age of recruitment affects the lifetime fitness of individuals and the growth rates of populations (Gaillard et al. 1998). Recruitment in this population of boobies occurs at ages from 1 to 10 years (Drummond et al. 2003), and most males and females recruit during the first six years of life (males, $4.32 \pm 0.09 \mathrm{yr}$; females, 3.80 $\pm 0.08 \mathrm{yr}$ ). Age of recruitment influenced the onset of reproductive senescence and longevity of males in a high-performing cohort and the lifetime reproductive success of females. Our results show that recruitment of males is strongly influenced by age and climate, while that of females is even more greatly influenced by age, but affected by climate only at intermediate ages, when favorable conditions are a particularly potent influence. One-year-old females generally decline to recruit whatever the conditions, whereas one-year-old males are likely to make an attempt if conditions are favorable. Females that are at least seven years old are strongly inclined to recruit, whatever the circumstances, but males of that age are highly responsive to climate. Strong dependence of male recruitment on climate could reflect energetic constraint on the possibility of successful reproduction of the smaller sex, especially in the youngest individuals, which probably harvest food inefficiently. At all ages examined, this sensitivity to climate could also reflect the making of prudent tradeoffs (Cam et al. 1998, Sanz et al. 2008), since delayed recruitment in males from a high-performing cohort is associated with longer lifespan at no cost in terms of lifetime reproductive success. Female lifespan, on the other hand, is unaffected by age of recruitment, but the earlier females recruit the more breeding attempts they make and the greater their lifetime reproductive success, although variance in both of these variables is high in females that recruit at two years of age. The larger bodies of females may buffer them against the risks of breeding in challenging circumstances.

Recruitment of females was more related to climate during the breeding season; that of males to climate before the breeding season. Assuming this difference reflects causality, it could result from differences in the roles of males and females in breeding (Grosbois and Thompson 2005, Jenouvrier et al. 2005), since male boobies start their breeding season earlier and females provide more food to the brood. Both sexes share all duties of parental care throughout the breeding cycle, but males arrive first on the breeding grounds and invest heavily in securing and defending territories (Nelson 1978, Stamps et al. 2002) and displaying ornaments (Velando et al. 2006a), and females deliver 2-5 times the mass of food provided by males (Guerra and Drummond 1995). Overall, these results make a case for complex effects of environmental variables in a nonlinear interaction between climate, age, and sex (Laakso et al. 2001, Croxall et al. 2002, Ezard et al. 2006, Kim et al. 2009). Temporal differences in the effects of climate on male and female recruitment point up the need to consider age and sex when making population projections for conservation purposes (Sæther et al. 2004, 2006).

\section{ACKNOWLEDGMENTS}

We are very grateful to Roger Pradel and Ana Sanz for their mathematical advice and to Alberto Velando and Sin-Yeon Kim for fruitful discussions. Two anonymous referees kindly improved a previous version of the manuscript. We are also grateful to José Luis Osorno, who made essential contributions 
to the long-term fieldwork and database, and to the many students who collected data during all these years. Funds were provided by UNAM (PAPIIT, IN230603, IN211491, IN2007023), CONACYT (81823, 47599, 34500-V, 4722N9407, D112-903581, PCCNCNA-031528, 31973H), Programa Marina Bueno and other grants from the Spanish Ministry of Science (reference CGL2006-04325/BOS). Permissions were provided by SEMARNAT, and logistical support by the Armada de México, the staff of the Parque Nacional Isla Isabel, and the fishermen of San Blas and Camichín.

\section{Literature Cited}

Anderson, D. J., and R. E. Ricklefs. 1987. Radio-tracking masked and blue-footed boobies (Sula spp.) in the Galápagos Islands. National Geographic Research 3:152-163.

Araújo, M. B., and C. Rahbek. 2006. How does climate change affect biodiversity? Science 313:1396-1397.

Becker, P. H., T. H. G. Ezard, J. D. Ludwigs, H. Sauer-Gurth, and M. Wink. 2008. Population sex ratio shift from fledging to recruitment: consequences for demography in a philopatric seabird. Oikos 117:60-68.

Bunce, A., S. J. Ward, and F. I. Norman. 2006. Are age-related variations in breeding performance greatest when food availability is limited? Journal of Zoology 266:163-169.

Burnham, K. P., and D. R. Anderson. 2002. Model selection and multimodel inference. Springer-Verlag, New York, New York, USA.

Cam, E., J. E. Hines, J.-Y. Monnat, J. D. Nichols, and E. Danchin. 1998. Are adult nonbreeders prudent parents? The kittiwake model. Ecology 79:2917-2930.

Castillo, A., and C. Chavez-Peón. 1983. Ecología Reproductiva e influencia del comportamiento en el control del número de crías en el bobo de patas azules, Sula nebouxii, en la Isla Isabel, Nay. Universidad Autónoma de Mexico (UNAM), Facultad de Ciencias, Mexico DF, Mexico.

Castillo-Guerrero, J., and E. Mellink. 2007. Long-distance natal dispersal in blue-footed boobies. Waterbirds 30:268270.

Choquet, R., A. M. Reboulet, R. Pradel, O. Gimenez, and J. D. Lebreton. 2004. M-SURGE: new software specifically designed for multistate capture recapture models. Animal Biodiversity and Conservation 27:207-221.

Coulson, T., E. A. Catchpole, S. D. Albon, B. J. T. Morgan, J. M. Pemberton, T. H. Clutton-Brock, M. J. Crawley, and B. T. Grenfell. 2001. Age, sex, density, winter weather, and population crashes in Soay sheep. Science 292:1528-1531.

Crespin, L., M. P. Harris, J.-D. Lebreton, M. Frederiksen, and S. Wanless. 2006. Recruitment to a seabird population depends on environmental factors and on population size. Journal of Animal Ecology 75:228-238.

Croxall, J. P., P. N. Trathan, and E. J. Murphy. 2002. Environmental change and Antarctic seabird populations. Science 297:1510-1514.

Drummond, H., R. Torres, and V. V. Krishnan. 2003. Buffered development: resilience after aggressive subordination in infancy. American Naturalist 161:794-807.

Durant, J. M., N. C. Stenseth, T. Anker-Nilssen, M. P. Harris, P. M. Thompson, and S. Wanless. 2004. Marine birds and climate fluctuation in the North Atlantic. Pages 95-106 in N. C. Stenseth, G. Ottersen, J. W. Hurrell, and A. Belgrano, editors. Marine ecosystems and climate variation. Oxford University Press, Oxford, UK.

Ezard, T. H. G., P. H. Becker, and T. Coulson. 2006. The contributions of age and sex to variation in common tern population growth rate. Journal of Animal Ecology 75:13791386.

Ezard, T. H. G., P. H. Becker, and T. Coulson. 2007. Correlations between age, phenotype, and individual contribution to population growth in common terns. Ecology 88: 2496-2504.
Frederiksen, M., M. P. Harris, F. Daunt, P. Rothery, and S. Wanless. 2004. Scale-dependent climate signals drive breeding phenology of three seabird species. Global Change Biology 10:1214-1221.

Gaillard, J.-M., M. Festa-Bianchet, D. Delorme, and J. Jorgenson. 2000. Body mass and individual fitness in female ungulates: bigger is not always better. Proceedings of the Royal Society B 267:471-477.

Gaillard, J. M., M. Festa-Bianchet, and N. G. Yoccoz. 1998. Population dynamics of large herbivores: variable recruitment with constant adult survival. Trends in Ecology and Evolution 13:58-63.

Grosbois, V., O. Gimenez, J. M. Gaillard, R. Pradel, C. Barbraud, J. Clobert, A. P. Møller, and H. Weimerskirch. 2008. Assessing the impact of climate variation on survival in vertebrate populations. Biological Reviews 83:357-399.

Grosbois, V., and P. M. Thompson. 2005. North Atlantic climate variation influences survival in adult fulmars. Oikos 109:273-290.

Guerra, M. del C., and H. Drummond. 1995. Reversed sexual size dimorphism and parental care: minimal division of labour in the blue-footed booby. Behaviour 132:479-496.

Harley, C. D. G., A. R. Hughes, K. M. Hultgren, B. G. Miner, C. J. B. Sorte, C. S. Thornber, L. F. Rodriguez, L. Tomanek, and S. L. Williams. 2006. The impacts of climate change in coastal marine systems. Ecology Letters 9:228-241.

Jenouvrier, S., C. Barbraud, B. Cazelles, and H. Weimerskirch. 2005. Modelling population dynamics of seabirds: importance of the effects of climate fluctuations on breeding proportions. Oikos 108:511-522.

Jenouvrier, S., C. Barbraud, and H. Weimerskirch. 2003. Effects of climate variability on the temporal population dynamics of southern fulmars. Journal of Animal Ecology 72:576-587.

Jones, I. L., F. M. Hunter, and G. J. Robertson. 2002. Annual adult survival of Least Auklets (Aves, Alcidae) varies with large-scale climatic conditions of the North Pacific Ocean. Oecologia 133:38-44.

Jones, I. L., F. M. Hunter, G. J. Robertson, J. C. Williams, and G. Vernon Byrd. 2007. Covariation among demographic and climate parameters in whiskered auklets Aethia pygmaea. Journal of Avian Biology 38:450-461.

Kim, S. Y., R. Torres, C. A. Dominguez, and H. Drummond. 2007a. Lifetime philopatry in the blue-footed booby. Behavioral Ecology 18:1132-1138.

Kim, S. Y., R. Torres, and H. Drummond. 2009. Simultaneous positive and negative density-dependent dispersal in a colonial bird species. Ecology 90:230-239.

Kim, S. Y., R. Torres, C. Rodríguez, and H. Drummond. 2007b. Effects of breeding success, mate fidelity and senescence on breeding dispersal of male and female bluefooted boobies. Journal of Animal Ecology 76:471-479.

Laakso, J., V. Kaitala, and E. Ranta. 2001. How does environmental variation translate into biological processes? Oikos 92:119-122.

Langvatn, R., S. D. Albon, T. Burkey, and T. H. CluttonBrock. 1996. Climate, plant phenology and variation in age of first reproduction in a temperate herbivore. Journal of Animal Ecology 65:653-670.

Lebreton, J.-D., K. P. Burnham, J. Clobert, and D. R. Anderson. 1992. Modeling survival and testing biological hypothesis using marked animals: a unified approach with case studies. Ecological Monographs 62:67-118.

Lee, D. E., N. Nur, and W. J. Sydeman. 2007. Climate and demography of the planktivorous Cassin's auklet Ptychoramphus aleuticus off northern California: implications for population change. Journal of Animal Ecology 76:337-347.

Lima, M., R. Julliard, N. C. Stenseth, and F. M. Jaksic. 2001. Demographic dynamics of a neotropical small rodent (Phyllotis darwini): feedback structure, predation and climatic factors. Journal of Animal Ecology 70:761-775. 
Ludwigs, J. D., and P. H. Becker. 2005. What do pairing patterns in common tern, Sterna hirundo, recruits reveal about the significance of sex and breeding experience? Behavioral Ecology and Sociobiology 57:412-421.

Nelson, J. B. 1978. The Sulidae: gannets and boobies. Oxford University Press, London, UK.

Nevoux, M., J. C. Barbraud, and C. Barbraud. 2008. Nonlinear impact of climate on survival in a migratory white stork population. Journal of Animal Ecology 77:1143-1152.

Nevoux, M., H. Weimerskirch, and C. Barbraud. 2007. Environmental variation and experience-related differences in the demography of the long-lived black-browed albatross. Journal of Animal Ecology 76:159-167.

Nichols, J. D., and W. L. Kendall. 1995. The use of multi-state capture-recapture models to address questions in evolutionary ecology. Journal of Applied Statistics 22:835-846.

Oro, D., A. Margalida, M. Carrete, R. Heredia, and J. A. Donázar. 2008. Testing the goodness of supplementary feeding to enhance population viability in an endangered vulture. PLoS ONE 3e4084. [doi: 10.1371/journal.pone.0004084]

Oro, D., and R. Pradel. 2000. Determinants of local recruitment in a growing colony of Audouin's gull. Journal of Animal Ecology 69:119-132.

Osorio-Beristain, M., and H. Drummond. 1993. Natal dispersal and deferred breeding in the Blue-footed Booby. Auk 110: 234-239.

Osorio-Beristain, M., and H. Drummond. 1998. Non-aggressive mate guarding by the blue-footed booby: a balance of female and male control. Behavioral Ecology and Sociobiology 43:307-315.

Pradel, R., C. M. A. Wintrebert, and O. Gimenez. 2003. A proposal for a goodness-of-fit test to the Arnason-Schwarz multisite capture-recapture model. Biometrics 59:43-53.

Root, T. L., J. T. Price, K. R. Hall, S. H. Schneider, C. Rosenzweig, and J. A. Pounds. 2003. Fingerprints of global warming on wild animals and plants. Nature 421:57-60.

Sæther, B. E., V. Grotan, P. Tryjanowski, C. Barbraud, and S. Engen. 2006. Climate and spatio-temporal variation in the population dynamics of a long distance migrant, the white stork. Journal of Animal Ecology 75:80-90.

Sæther, B. E., W. J. Sutherland, and S. Engen. 2004. Climate Influences on avian Population dynamics. Advances in Ecological Research 35:185-209.

Sandvik, H., K. E. Erikstad, R. T. Barrett, and N. G. Yoccoz. 2005. The effect of climate on adult survival in five species of North Atlantic seabirds. Journal of Animal Ecology 74:817831.

Sanz, A., G. Tavecchia, R. Pradel, E. Minguez, and D. Oro. 2008. The cost of reproduction and experience-dependent vital rates in a small petrel. Ecology 89:3195-3203.

Sillett, T. S., R. T. Holmes, and T. W. Sherry. 2000. Impacts of a global climate cycle on population dynamics of a migratory songbird. Science 288:2040-2042.

Simonoff, J. S. 1996. Smoothing methods in statistics. SpringerVerlag, New York, New York, USA.
Stamps, J., M. Calderón-de Anda, C. Perez, and H. Drummond. 2002. Collaborative tactics for nestsite selection by pairs of blue footed boobies, Sula nebouxii. Behaviour 139: $1383-1412$.

Stearns, S. C. 1992. The evolution of life histories. Oxford University Press, Oxford, UK.

Stenseth, N. C., A. Mysterud, G. Ottersen, J. W. Hurrell, K. Chan, and M. Lima. 2002. Ecological effects of climate fluctuations. Science 297:1292-1296.

Stenseth, N. C., G. Ottersen, J. W. Hurrell, and A. Belgrano. 2005. Marine ecosystems and climate variation. Oxford University Press, Oxford, UK.

Sydeman, W. J., M. M. Hester, J. A. Thayer, F. Gress, P. Martin, and J. Buffa. 2001. Climate change, reproductive performance and diet composition of marine birds in the southern California Current system, 1969-1997. Progress in Oceanography 49:309-329.

Tavecchia, G., T. Coulson, B. J. T. Morgan, J. M. Pemberton, J. C. Pilkington, F. M. D. Gulland, and T. H. Clutton-Brock. 2005. Predictors of reproductive cost in female Soay sheep. Journal of Animal Ecology 74:201-213.

Tavecchia, G., R. Pradel, M. Genovart, and D. Oro. 2007. Density-dependent parameters and demographic equilibrium in open populations. Oikos 116:1481-1492.

Thomas, C. D., et al. 2004. Extinction risk from climate change. Nature 427:145-148.

Thompson, P. M., and V. Grosbois. 2002. Effects of climate variation on seabird population dynamics. Directions in Science 1:51-52.

Velando, A., and C. Alonso-Alvarez. 2003. Differential body condition regulation by males and females in response to experimental manipulations of brood size and parental effort in the blue-footed booby. Journal of Animal Ecology 72:846856.

Velando, A., R. Beamonte-Barrientos, and R. Torres. $2006 a$. Pigment-based skin colour in the blue-footed booby: an honest signal of current condition used by females to adjust reproductive investment. Oecologia 149:535-542.

Velando, A., H. Drummond, and R. Torres. 2006b. Senescent birds redouble reproductive effort when ill: confirmation of the terminal investment hypothesis. Proceedings of the Royal Society B 273:1443-1448.

Velarde, E., E. Ezcurra, M. A. Cisneros-Mata, and M. F. Lavin. 2004. Seabird ecology, El Niño anomalies, and prediction of sardine fisheries in the Gulf of California. Ecological Applications 14:607-615.

Veran, S., O. Gimenez, E. Flint, W. L. Kendall, P. F. Doherty, Jr., and J. D. Lebreton. 2007. Quantifying the impact of longline fisheries on adult survival in the black-footed albatross. Journal of Applied Ecology 44:942-952.

Votier, S. C., T. R. Birkhead, D. Oro, M. Trinder, M. J. Grantham, J. A. Clarck, R. H. McCleery, and B. J. Hatchwell. 2008. Recruitment and survival of immature seabirds in relation to oil spills and climate variability. Journal of Animal Ecology 77:974-983. 